\title{
5
}

\section{Protesting policy and practice in South Korea's nuclear energy industry}

\author{
Lauren Richardson
}

\section{Abstract}

Japan's March 2011 (3/11) crisis spurred a revival in anti-nuclear activism around the globe. This was certainly the case in South Korea, Japan's nearest neighbour, which was subject to some of the nuclear fallout from Fukushima. This chapter examines the puzzle of why the South Korean antinuclear movement was apparently powerless in the face of its government's decision to ratchet up nuclear energy production post-3/11. It argues that its limitations stem from the highly insulated nature of energy policymaking in South Korea; the enmeshing of nuclear power in the government's 'Green Growth Strategy'; and certain tactical insufficiencies within the movement itself. Notwithstanding these limitations, the movement has successfully capitalised upon more recent domestic shocks to the nuclear power industry, resulting in a slight, yet significant, curtailing of the South Korean government's nuclear energy capacity targets.

\section{Introduction}

The March 2011 (3/11) earthquake in northeastern Japan and ensuing nuclear meltdown at the Fukushima Daiichi plant had profound reverberations for the global nuclear industry. In the wake of the disaster, countries as far-reaching as Germany and Switzerland brought their 
nuclear energy programs to a complete halt. Closer to the source of the calamity, the Taipei government initiated a gradual phase-out of its nuclear reactors and suspended plans for the construction of a fourth nuclear plant. These policy shifts were precipitated by nationwide anti-nuclear demonstrations, which erupted in response to the Fukushima crisis. Somewhat surprising, however, was that Japan's nearest neighbour, South Korea, reacted to the complete contrary. Despite the fact that Korean territory was subject to some of the nuclear fallout from Fukushima (see Hong et al. 2012), the South Korean government proceeded to ratchet up its nuclear energy program post-3/11 and pushed ahead with plans to become a major exporter of nuclear technology. Indeed, within only months of Japan's disaster, South Korean President Lee Myung-bak reiterated his administration's goal of doubling the number of domestic reactors, and reaffirmed nuclear technology as a primary export focus.

This response was puzzling for a number of reasons. First, similarly to the cases of Germany, Switzerland, and Taiwan, the South Korean anti-nuclear movement expanded to unprecedented proportions in the aftermath of Fukushima, yet ostensibly to no avail. This expansion was driven by a marked decline in public trust in the safety of nuclear reactors, and witnessed activists mounting a formidable challenge to nuclear energy policy. Moreover, since overthrowing the nation's longstanding authoritarian regime in the late 1980s, South Korean civil society has evolved to wield powerful influence across a variety of policy domains; activists, though, were apparently powerless in the face of their government's decision to increase nuclear-generating capacity. This is somewhat perplexing given that, in the very same year of the Fukushima calamity, South Korean civic groups contributed to undercutting a proposed security accord between Seoul and Tokyo, and 'comfort women' victims compelled their foreign ministry to pursue compensation from Japan more vigorously on their behalf - to name but two realms of policy influence.

Why then was South Korea's anti-nuclear movement unable to subvert the South Korean government's nuclear energy policy? Does the movement's lack of evident success suggest that it exerted no tangible influence on nuclear energy development in South Korea? What factors have served to impede its effectiveness? This chapter addresses these questions through an analysis of the movement's campaign to alter policy and practice in the South Korean nuclear energy industry from the late 1980s to 2016. As the challenges encountered by the movement stem in part from the structural 
development of nuclear energy in South Korea, the chapter begins by outlining the evolution of this process. It proceeds to assess the efficacy of the anti-nuclear movement in pre- and post-Fukushima contexts, with reference to its aims and pressure tactics. It then assesses the reasons behind the government's lack of responsiveness to the movement, before finally examining two emergent encumbrances to nuclear energy policy.

The chapter advances three broad arguments. First, the anti-nuclear movement has had considerable success in preventing the construction of nuclear waste disposal sites; this endeavour has been more fruitful than strategies that sought to undermine the establishment of new nuclear power plants. Second, the movement's inability to abort nuclear energy production stems from the highly insulated nature of energy policymaking in South Korea, the enmeshing of nuclear power in the government's 'Green Growth Strategy', and certain tactical insufficiencies in the anti-nuclear movement. Third, notwithstanding these limitations, the movement has capitalised upon recent domestic shocks to the nuclear power industry, resulting in a curtailing of the government's nuclear energy capacity targets.

\section{The evolution of South Korea's nuclear energy policy}

Since its post-Korean War (1950-53) inception, energy policy in South Korea has been driven by the need to spur economic growth, minimise dependence on imports, and ensure long-term energy security. In the late 1950s, the South Korean government opted to develop a nuclear power program as a means to fuel the restoration of its war-shattered economy. Officials presumed that nuclear reactors would provide a stable source of energy, facilitate export-oriented growth, and reduce the nation's reliance on costly oil, coal, and gas imports. Toward this end, Seoul joined the International Atomic Energy Agency (IAEA) in 1957, and thereafter enacted Framework Act No. 483 on Atomic Energy (1958) and established an Office of Atomic Energy (1959).

Under the iron grip of a succession of authoritarian leaders from the 1960 s to the late 1980s, nuclear energy legislation proceeded mostly unhindered by public resistance. Indeed, the Park Chung-hee dictatorship (1961-79) was quick to charge would-be demonstrators with violating anti-communism and national security laws, and resorted to barrages 
of tear gas and martial law to restrain them. It was against this backdrop that the nation's first reactor, a small research unit, was brought to criticality in 1962. Some 10 years later, the Park government commissioned the construction of the Kori nuclear power plant in the port city of Busan, and this began generating in 1978 (Hwang and Kim 2013: 196).

In addition to the authoritarian milieu, South Korea's alliance with the United States constituted a further driving force in its development of nuclear energy. Once Seoul embarked on its nuclear power program, a confluence of interests emerged between the American nuclear industry, business conglomerates (chaebol), and officials in South Korea. Nuclear power companies in the US had a specific agenda to promote the advancement of nuclear technology in non-communist countries, and thus viewed South Korea as an attractive business prospect. In fact, the American firm Combustion Engineering (later incorporated into Westinghouse Electric) supplied South Korea with its first nuclear reactor in 1978 - the Kori-1 unit — and thereupon imparted technological knowhow to the fledgling industry.

The US government, meanwhile, sought a degree of control over its ally's nuclear energy policy; this was predicated on dissuading South Korea from developing an indigenous nuclear weapons capability. Prompted by mounting military pressure from Pyongyang and the withdrawal of thousands of US troops from South Korea in 1971, Park started harbouring aspirations of nuclear weapons development and proliferation (Hayes and Moon 2011). Through the enactment of the Agreement for Cooperation between the Government of the United States of America and the Government of the Republic of Korea Concerning Civil Uses of Atomic Energy in 1972, Washington attempted to curb these ambitions by pledging to provide nuclear materials and technology to Seoul on the condition that they be used exclusively for energy production purposes. The terms of the agreement further undermined Seoul's nuclear weapons potential by prohibiting uranium enrichment and limiting its fuel cycle options and raw material supply. When the Korea Atomic Energy Research Institute attempted to circumvent these terms by purchasing reprocessing plants from Belgium in the mid-1970s, the US and Canadian governments thwarted the deal by exerting financial leverage vis-à-vis Seoul, and Washington further threatened to cut off support for its ally's nuclear power program (Hayes and Moon 2011: 51-3). Under the weight of this pressure, Park eventually abandoned his weapons development and proliferation plans at the end of the decade. 
Throughout the early to mid-1980s, the expansion of South Korea's nuclear energy capacity proceeded mostly unencumbered by civic dissent. This was largely owing to the preoccupation of the populace with achieving democratisation (Leem 2006). In this context, the state-owned Korea Electric Power Company (KEPCO) oversaw the construction of an additional eight reactors, through the assistance of American nuclear firms. By the end of the decade, South Korea's nuclear energy industry had evolved to supply 45 per cent of the nation's energy needs and had virtually attained technical self-reliance. Nuclear power thus became closely correlated with South Korea’s rapid industrialisation and economic rise.

\section{The bottom-up movement against nuclear energy}

As the transition to democracy began in the late 1980s, however, the nuclear energy industry began to encounter significant social resistance. After a decade of sustained civil uprisings against the authoritarian leadership, South Korean citizens started to question Park's development model, in particular its driving force of nuclear energy. This questioning, which was fueled by increasing political liberalisation, gradually gave rise to a nascent anti-nuclear movement. In its early stages, this movement remained fairly localised around nuclear reactor sites. Yet the Fukushima crisis served to galvanise and encourage its transnational expansion. Although the movement's overarching objective of achieving a nuclearfree South Korea ultimately proved abortive, it did succeed in stymieing the construction of a number of nuclear waste disposal sites. This section examines the movement's opposition tactics before and after $3 / 11$.

\section{Phase 1: Pre-Fukushima}

The South Korean anti-nuclear movement emerged as an amalgamation of various environmental and other civic-minded groups. Spurred in part by the numerous nuclear power plant-related accidents that had occurred by the end of the 1980s, including the Chernobyl disaster, citizens joined forces to prevent further environmental damage and curb the nation's steadily increasing pollution. As a first step, they jointly established the National Headquarters for Nuclear Power Eradication, and thereupon launched a bottom-up campaign against nuclear energy. 
One of the first major rallying points of the movement was the matter of radioactive waste disposal. Given that close to 50 per cent of the nation's electricity was being derived from nuclear power by the 1980s, spent fuel repositories were reaching capacity and the storage of radioactive waste had begun to pose a formidable challenge. Activists perceived this state of affairs as a potential environmental disaster. When the government first announced its candidate sites for nuclear waste disposal in 1986-and every instance thereafter-impassioned civic resistance thus followed. Brandishing messages about the dangers of nuclear materials, citizens staged large-scale protests at government complexes and proposed waste sites. These early grassroots efforts met with overwhelming success: over a period of eight years, the anti-nuclear movement thwarted the construction of 12 nuclear waste disposal sites (Sayvetz 2012).

In an attempt to circumvent further public obstruction, the South Korean government began targeting remote locales to play host to waste depositories. In the mid-1990s, officials designated Gulup Island, a small landmass off South Korea's western coast, as a potential site. This plan was instigated without public consultation and when news of it was leaked to the public, anti-nuclear activists rallied in anger. The Korean Federation for Environmental Movements (KFEM) elected to head a campaign to prevent the site's construction. Boasting a membership of more than 13,000, the KFEM worked in tandem with various civic groups to advocate for the Gulup Island residents, who were strongly averse to the prospect of a nuclear waste dump in their residential vicinity (Sayvetz 2012). In a show of broad-based consensus against the proposed site, the KFEM convened mass rallies and filed an oppositional petition that attracted thousands of signatures.

When the government belatedly agreed to convene a public hearing regarding the site, representatives from a number of civic groups voiced their concerns about the presence of a geological fault on the island. Their apprehensions, however, ostensibly fell on deaf ears. Public pressure thus continued to mount and, in the spring of 1995 , over 300 residents in the nearby Deokjeok Island-who were also fearful of the site's potential consequences - staged a protest in front of the Ministry of Science and Technology in Seoul. Faced with this unrelenting opposition, government officials were impelled to solicit experts from the IAEA to conduct a survey on the proposed site. Their findings revealed the presence of a fault, 
confirming residents' suspicions that the site was particularly perilous for the storage of nuclear waste. In light of this development, the central government decided to abort the Gulup Island plan in November 1995.

The movement continued to challenge the construction of radioactive waste sites throughout the 1990s and into the early twenty-first century. These attempts tended to remain localised in nature and dissipated once a proposal was successfully undermined.

\section{Phase 2: Post-Fukushima}

Following the meltdown of the three reactors in Fukushima, South Korea's anti-nuclear movement underwent somewhat of a resurgence. This was characterised by the mobilisation of a broader spectrum of activists and an increase in the breadth of the movement's anti-nuclear activities. As images of the triple meltdown at the Fukushima Daiichi plant filtered through South Korean media outlets, various religious groups, unions, co-ops, professional associations, non-governmental organisations, academics, and parents groups joined the appeal for a nuclear-free future. Moreover, the $3 / 11$ crisis spurred the South Korean movement to transnationalise its anti-nuclear efforts through joining forces with like-minded activists in the region. This was instigated by a group of Catholic South Korean dioceses who pledged to form an East Asian civil society network with anti-nuclear activists in Japan and China; their objective was to present a united front of opposition to the nuclear power industry regardless of the tensions between their respective countries. As described in their initial prospectus, 'the more we share information on the dangers on nuclear power and spread technology and wisdom regarding natural energy, the more East Asia will become the center of peace, not conflict; of life, not destruction' (East Coast Solidarity for Anti-Nuke Group 2012). Under the nomenclature of the East Coast Solidarity for Anti-Nuke Group, the group debuted on the first anniversary of the Fukushima disaster with a declared membership of 311 citizens, signifying that the South Korean movement was no longer a domestic phenomenon localised around nuclear waste sites.

In accordance with the expansion of its constituents, the movement increased the scope of its anti-nuclear efforts in the aftermath of Fukushima. Moving beyond the initial focus of countering the construction of new waste storage sites and plants, activists began to advocate more broadly for the cessation of nuclear energy production; accordingly, they targeted existing 
plants. The logic driving the movement's post-Fukushima campaign was essentially fourfold: (1) uranium sources will eventually be exhausted, and therefore nuclear energy is not a viable permanent energy source; (2) most of the developed countries around the world are no longer constructing new nuclear reactors and, since Fukushima, are seriously rethinking their nuclear energy policies; (3) when factoring in the social costs, nuclear energy cannot be considered cost-effective; and (4) as the mining and processing of uranium produces carbon dioxide $\left(\mathrm{CO}_{2}\right)$ emissions, nuclear power cannot be conceived of as an environmentally friendly source. Meanwhile, the overarching logic informing the movement was that Japan's 'March 11 disaster has proven that nuclear power plants are not safe' (Nagata 2012).

First among the anti-nuclear movement's post- $3 / 11$ objectives was to nullify the lifespan extensions of the nation's two oldest nuclear reactorsKori-1 and Wolsong-1. The former unit, which was already running beyond its technological lifespan, had experienced a number of technical problems in the spring of 2011, and was consequently temporarily shut down. Yet shortly thereafter, nuclear officials declared it suitable for operation and allowed it to resume power generation. Likewise, the latter unit, which began operating in 1983 at a plant in North Gyeongsang province, was taken offline for extended maintenance in June 2009. As its operating license was due to expire in 2012, Korea Hydro \& Nuclear Power (KHNP) spent $\$ 560$ billion (US\$509 million) on refitting the unit with the hope of prolonging its lifespan. Ultimately, the reactor was cleared for restart in June 2011.

These decisions by nuclear energy officials were made in close succession to the Fukushima disaster, and thus aroused fears among local residents of a similar catastrophe occurring in their own vicinity. Under the banner of a group called Collective Action for a Nuclear Free Society, residents demanded that the life extensions of the reactors be nullified. Toward this end, they staged protests in front of the Nuclear Safety and Security Commission (NSSC) in Seoul, where officials deliberated the fate of the reactors, and chanted anti-nuclear slogans. In spite of these objections, however, nuclear officials permitted Kori-1's continued operation. And although they agreed to shut down Wolsong-1 at the conclusion of its lifespan in November 2012, they later backtracked, granting permission for it to restart in February 2015 and operate for a further 10 years. These two decisions constituted a major setback for the movement. 
In addition to focusing on aged reactors, the anti-nuclear movement continued on its mission to abort the construction of new nuclear power plants. Activists concentrated on the candidate sites of Samcheok and Yeongdeok, two cities on the east coast of South Korea in which the government proposed to build eight new reactors (four at each site). The local government of Samcheok had originally agreed to host a nuclear power plant in 2010. Yet following the Fukushima disaster, anti-nuclear sentiment swept throughout the city, culminating in the formation of the Pan-Citizen Alliance for Cancelling the Samcheok Nuclear Power Plant. To signal their changed stance on nuclear power to the central government, the city residents elected a new mayor, Kim Yang-ho, who had campaigned on an anti-nuclear platform. In order to elicit a collective anti-nuclear expression, Kim held a referendum in October 2014. As he anticipated, the majority of citizens indicated their opposition to the plant's construction: among the 69.8 per cent of the voting population who participated in the referendum, 85 per cent voted against the proposed site. Due to the fact that the referendum was not legally sanctioned, however, the national government declared it non-binding and thus ignored the result.

In the second candidate city of Yeongdeok, a similar outcome transpired. Being a rural and coastal county with a dwindling population and struggling economy, Yeongdeok's residents had initially been enthused about the prospect of economic revitalisation that a nuclear power plant would offer. Not only would it bring much-needed employment opportunities, but the South Korean government had pledged to provide \#1.5 trillion (US $\$ 1.35$ billion) over a 60 -year period, to compensate for any potential associated dangers. Having lost their earlier (2005) bid to host a storage site for low-level radioactive waste, the citizens of Yeongdeok were particularly keen to secure the nuclear power plant venture. Their enthusiasm quickly dissipated, however, in the face of Japan's 3/11 disaster. Indeed, residents had not foreseen the possibility of tsunami damage to the plant when originally submitting their host bid. In the aftermath of Fukushima, local citizens thus called for a county referendum to overturn the plan. In this instance, the mayor was unwilling to support the initiative and therefore residents organised it on their own accord. Perhaps owing to this lack of official backing, the referendum failed to attract the requisite one-third of voters for it to hold legal sway (Kim 2015). In any case, national officials dismissed both the Samcheok and Yeongdeok voter outcomes on the grounds that central government projects are not subject to local referenda results. 
Evidently, the pressure tactics of the South Korean anti-nuclear movement have produced mixed results. Early protests were successful in undermining nuclear waste site proposals and plans for the construction of a small number of nuclear power plants. Yet in the post-Fukushima period, the movement largely failed in its aims to abrogate the lifespan extensions of aged reactors and reverse site selection decisions for new nuclear power plants.

\section{Explaining the limited policy change}

Despite the magnitude of the Fukushima crisis and ensuing tide of pressure from the anti-nuclear movement, Seoul's nuclear power policy showed no immediate signs of deceleration-at least on the surface. The disaster only prompted limited government measures aimed at counteracting potential contamination from Japan's meltdown, and enhancing the safety of domestic nuclear installations. In the two months following 3/11, all 30,000 passengers that entered South Korea from Japan (by ship or aircraft) were screened for radioactivity; only two people, however, required decontamination (Korean Government 2011). Over the same two months, the central government ordered nuclear officials to carry out a special safety inspection of all nuclear power plants throughout the country, yet, ultimately, no abnormalities were detected. Finally, in June 2011, the South Korean National Assembly passed a bill to establish the NSSC, a regulatory body tasked with protecting public health and safety.

Together these measures constituted the extent of the South Korean government's responsiveness to 3/11 and the subsequent pressure from the anti-nuclear movement. South Korea continues to stand as the sixth largest consumer of nuclear energy in the world, second in Asia only to Japan. There remain 24 nuclear reactors operating nationwide, with another five under construction. Government officials continue to emphasise the safety and low-cost efficiency of nuclear power, while largely eschewing the development of renewable energy sources. Expanding the nuclear energy industry is still a national strategic priority, as exemplified in the Ministry of Science and Technology's (2006) Third Comprehensive Plan for Nuclear Energy Development (2007-11). The government predicted in this report that the nation would derive 59 per cent of its electricity from nuclear power sources by 2030 . 
In addition to these domestic ambitions, nuclear energy technology has evolved to become a major export industry for South Korea. The Ministry of Knowledge Economy intends to export another 80 reactors, worth a total of US $\$ 400$ billion, by 2030 . The nation secured its first major international contract in 2009, when KEPCO signed a US $\$ 40$ billion deal to construct four nuclear reactors for the United Arab Emirates (UAE). Undeterred by the Fukushima meltdown, President Lee embarked on an official visit to the UAE on 13 March 2011-a mere two days after Japan's crisis began to unfold-to reaffirm his plans for future energy cooperation. Besides the UAE deal, Seoul has secured a US $\$ 173$ million contract to build a nuclear research reactor in Jordan, and to construct several reactors in Saudi Arabia worth a total of US\$2 billion. Other target export countries for South Korea's nuclear industry include China, Finland, Hungary, Indonesia, Malaysia, Turkey, and Vietnam.

What explains the failure of the anti-nuclear movement to subvert the development of nuclear energy in South Korea? Pressure tactics cannot singularly account for the limited policy change. Rather, a combination of three factors have served to militate against substantial nuclear power reform: (1) the highly insulated and top-down nature of nuclear energy policymaking in South Korea - this has restricted the number of legislative handles around which activists can mobilise to influence policy decisions; (2) the centrality of nuclear energy to the South Korean government's Green Growth Strategy, a factor that has legitimated its continued expansion; and (3) shortcomings in the anti-nuclear movement's pressure strategy, specifically, its laxness in articulating a feasible alternative energy strategy to nuclear power.

\section{The insularity of nuclear power policymaking}

The primary hurdle faced by the movement has been the elite-driven nature of policymaking on nuclear energy. In contrast to the many other policy domains in South Korea that allow for substantial input from citizens, decisions on nuclear energy continue to be formulated exclusively by government officials and technocrats, in a highly insulated environment. The key actors engaged in this process include the Ministry of Commerce, Industry and Energy; the Ministry of Trade, Industry and Energy; the Ministry of Science, ICT and Future Planning; the NSSC; and various chaebol and bureaucratic authorities. Each of these institutions is in turn informed by pro-nuclear politicians and technocrats, 
producing an iron triangle of decision-making that excludes civil society. This triangular structure was particularly reinforced with the installation of Lee—a former chaebol leader (Hyundai executive)—as South Korean president in 2008.

As a corollary of this elite-driven process, nuclear energy policy is implemented through a top-down dynamic. This has been characterised by a 'decide-announce-defend' sequence (Norman and Nagtzaam 2016: 250), whereby the central government enacts a policy, proceeds to impose it on local government and citizens, and then seeks to placate any objections by offering financial rewards and other incentives. This sequence was vividly evinced in the Gulup Island fiasco. However, as this strategy has proved abortive on a number of occasions, the government has attempted since 2004 to move toward a slightly more consultative mechanism that incorporates citizens' preferences. Activists continue, though, to face significant barriers in shaping the nuclear energy agenda. The elite-driven and top-down dynamic of the policy process has in fact steered their pressure tactics away from government lobbying, toward the more viable strategy of obstructing policy implementation.

\section{Nuclear power as 'green' energy}

A further inhibiting factor for the movement has been the enmeshing of nuclear power in the South Korean government's Green Growth Strategy. Essentially, this has added another layer of insularity to nuclear energy policy in South Korea.

As a consequence of South Korea's rapid industrialisation over the last few decades, its greenhouse gas emissions virtually doubled between 1990 and 2005-an increment exceeding most of the Organisation for Economic Co-operation and Development (OECD) countries. At the same time, Seoul's annual mean temperature increased by 1.5 degrees Celsius, surpassing the global average of 0.7 degrees Celsius (von Hippel, Yun, and Cho 2011). These developments, coupled with an emergent international consensus on the need to address climate change, forced the South Korean government to consider ways to curtail its $\mathrm{CO}_{2}$ emissions. Being at once low-carbon and cost-effective, nuclear energy was seized upon by South Korean officials as a convenient solution to the nation's environmental and climate woes, and also as a means to deal with rising energy demands. In 2009, the Lee administration announced a national Green Growth Strategy premised on three major objectives: reducing fossil 
fuel use, tracking greenhouse gas emissions, and establishing several new nuclear power plants. Renewable energy was relegated only a marginal status under the plan.

This linking of nuclear power to the national environmental and climate strategy was institutionalised through the government's Five Year Plan for Green Growth (2009-13), and the Framework Act on Low Carbon, Green Growth (2010). As a result of this process, the political opportunity structure surrounding nuclear energy became less favourable to activists. The discursive framing of nuclear power, as both a means to reduce carbon emissions and promote energy independence, enabled the South Korean government to legitimise its plans to expand nuclear power domestically and export nuclear technology abroad. Indeed, Lee boasted to his constituencies that the planned export of four reactors to the UAE would equate to ' 40 million tons of carbon mitigation' (Lee 2010: 11-12).

To challenge this stance of the government, the anti-nuclear movement has attempted to counter-frame nuclear power as an environmentally unfriendly energy source. As previously mentioned, activists have argued that the mining and processing of uranium produces $\mathrm{CO}_{2}$ emissions. The movement has furthermore underscored the clause of the South Korea-US atomic energy agreement, which prohibits the reprocessing of spent fuel, and thus renders the necessity of environmentally hazardous radioactive waste sites. As many of South Korea's nuclear power plants are located in coastal areas that are subject to occasional earthquakes, activists have also raised the possibility of the occurrence of a Fukushimastyle disaster. This counter-frame, however, has yet to tip the cost-benefit analysis of nuclear energy by the wider populace. Indeed, there remains an overriding belief within South Korean society that nuclear power holds the key to combating climate change, as argued by the government.

\section{Tactical insufficiencies in the anti-nuclear movement}

The limited policy change in nuclear energy development can further be attributed to insufficiencies in the tactics of the anti-nuclear movement. Throughout their campaign against nuclear power, activists have neglected to formulate a feasible alternative energy source. Instead of demanding new policies (Hermanns 2015: 276), they have tended towards the reactionary tactics of undercutting policy implementation and emphasising the hazards inherent in nuclear energy. Given that South Korea is lacking in natural resources and its economy is structured around manufacturing, 
this approach of the movement has been problematic for the offsetting of nuclear power. In the absence of a strategy delineating how the nation's energy needs might otherwise be met-accounting both for energy security issues and projected industrialisation - it is improbable that the South Korean government would eschew nuclear power as a major energy source. Formulating such a strategy is all the more necessary in light of the nation's dense population, relatively small landmass, and mountainous terrain, all of which render certain forms of renewable energy-such as wind farms-less conceivable than in other countries.

And while the anti-nuclear movement has significantly increased in scope since Fukushima, its pressure tactics have not resulted in a marked change in public opinion vis-à-vis nuclear power. According to annual polls conducted by the Korea Nuclear Energy Agency, South Korean citizens have upheld consistent views about the importance of nuclear-generated energy throughout recent years, with national support for nuclear power plants hovering between 80 per cent and 90 per cent-even after Fukushima. This has served to further bolster the government's mandate to expand its nuclear energy program. The $3 / 11$ disaster did, however, result in lowered perceptions regarding the safety of nuclear reactors and radioactive waste management in South Korea, with 39 per cent and 24 per cent of survey respondents expressing their confidence in these respective realms. Additionally, polls conducted one year prior to and one year after Fukushima indicated a decline of 8 per cent (from 28 per cent to 20 per cent) in local acceptance of nuclear power (Dalton and Cha 2016). These statistics reflect the fact that opposition to nuclear power is highly localised to rural areas — where nuclear power plants and waste sites are concentrated-while support for nuclear power rests with the larger cities, such as Seoul, where the power-brokers reside and nuclear power plants are a rare sight.

In effect, the downturn in local approval of and confidence in the safety of nuclear reactors has complicated the policy implementation process in South Korea. At the same time, though, the sustained broad-based support for nuclear power generation has functioned to attenuate the pressure tactics of the anti-nuclear movement. 


\section{New challenges to South Korea's nuclear energy industry}

Notwithstanding the limitations of the anti-nuclear movement in shaping energy policy in South Korea, recent years have seen the emergence of two new challenges to the government's nuclear power strategy. Manifesting both endogenously and exogenously, effectively these have sent shockwaves throughout the industry, forcing Seoul to curb its generating capacity ambitions. For its part, the anti-nuclear movement has seized upon these shocks as opportunities to whip up further opposition to nuclear energy among South Korea's populace.

\section{Corruption scandals}

The first of these challenges manifested as a series of corruption scandals implicating nuclear officials, and a consequent erosion of public trust in nuclear energy regulation. As part of Seoul's bid to expand its nucleargenerating capacity, 11 new reactors had been planned for construction in the period 2012-21. This proposal was derailed, however, when it was found-during a routine inspection-that the plant manager had covered-up a reactor power failure (KHNP 2012). When the reactor in question had lost power, the emergency diesel generator failed to start, signalling a host of potential dangers. The plant manager refrained from reporting the mishap due to a fear of inciting a public backlash and 'worsening the plant's credibility' (IAEA-NSNI 2012: 3).

Given Kori's location in South Korea's second-most populous city of Busan, this act of cover-up provided ample opportunity for the antinuclear movement to stoke public concerns about regulatory practices. Thus, amidst the controversy, the KFEM and the No Nukes Busan Citizen Countermeasure Commission simulated a radioactive leak (on the scale of the Chernobyl disaster) at the plant, to determine the probable effects. The results were published in a report, and predicted that such an accident would produce roughly 900,000 casualties in Busan, and 628 trillion (US\$533 billion) worth of property damage (Yi 2012). This scenario, which was reminiscent of the safety regulatory failure at the Fukushima Daiichi plant, struck widespread fear in the minds of residents. While a panel of experts from the IAEA proceeded to declare the two reactors as safe, their assurances failed to allay the concerns of local citizens who were quickly losing trust in nuclear officials (IAEA 2012). 
On the heels of this incident a second corruption scandal occurred, further highlighting the lack of transparency in the regulation of nuclear power plants in South Korea. This unravelled in November 2012, when regulators discovered that at least 5,000 small reactor components at the Yeonggwang nuclear power plant lacked proper certification, and that at least 60 of the quality assurance certificates for these components were fake. After launching an official investigation, the KHNP announced that between 2003 and 2012, the plant had been supplied with a total of 7,682 items with forged quality certificates (LaForge 2013-14). In light of these revelations, the KHNP was compelled to shut down two of the plant's six reactors until the dubious reactor components were replaced. As citizen protests erupted over the controversy, nuclear authorities were prompted to inspect the components of all 23 reactors nationwide. This led to the discovery of copious forged safety certificates for reactor parts at the Kori and Wolseong plants. Consequently, the Kori-2 and Shin Wolseong-1 units were shut down in June 2013, and Kori-1 and Shin Wolseong-2 were ordered to remain offline while the unauthorised parts were refitted. In the ascription of culpability for these scandals, 100 people were indicted on bribery charges, including a former chief executive of the KHNP and a vice president of KEPCO (LaForge 2013-14).

Once again, these events triggered an upsurge in anti-nuclear ferment in South Korea. Citizens attributed the corrupt practices in safety certification to the culture of secrecy shrouding the nuclear energy industry. These sentiments were evinced in protests that erupted in response to the shut down of the Yeonggwang reactors, which attracted as many as 2,500 citizens. Calling for an overall safety review of South Korea's nuclear power plants, participants burned effigies of the KHNP and brandished placards claiming, 'We feel uneasy!' To placate the public outcry, Cho Seok, the chief executive officer of the KHNP, issued a public apology in September 2013, conceding that the corruption scandals constituted the 'utmost crisis' ever faced by the nuclear sector, and vowed to reform South Korea’s corporate culture.

Together these controversies engendered a loss of overall public trust in the government's capacity to regulate nuclear energy production. This outcome was inevitably reinforced by the parallels that citizens drew between the regulatory shortcomings at Fukushima Daiichi and that of their national nuclear power plants. 


\section{Cyber-attacks on nuclear power plants}

The second formidable challenge to South Korea's nuclear energy program emerged in the form of a cyber-attack. This occurred in December 2014, when a hacker leaked the partial blueprints and operating manuals for three domestic nuclear reactors, in addition to the personal data on 10,000 KHNP employees (Baylon, Livingstone, and Brunt 2015). The material was first published online via a blog, and then on a Twitter account under the profile 'president of the anti-nuclear reactor group'. The hacker, whose identity was unknown (the South Korean government suspected Pyongyang), issued a threat to the effect that unless three specific reactor units-Kori-1, Kori-3, and Wolseong-2-were shut down by Christmas, they would systematically be destroyed and further data would be published online. 'Will you take responsibility when these blueprints, installation diagrams and programs are released to the countries that want them?' the hacker threatened in Korean. The three nuclear reactors at the centre of the controversy had long been targeted by the anti-nuclear movement, given their close proximity to populous areas.

Despite having accessed the reactors' blueprints and manuals, however, the hacker was unable to obtain critical technical data pertaining to the nuclear facilities; indeed, this information is stored securely within the KHNP's control monitoring system, which is separate from its internal network. The attacks nevertheless prompted the government to raise its cyber-crisis alert level to 'attention' - the second on a five-step scale-and to run a series of cyber-warfare drills on its various nuclear power plants. More worrisome for government and nuclear officials was that the cyberattack and its attendant threats provided further fuel for the anti-nuclear movement and stirred greater social unrest among residents in the Kori and Wolseong plant vicinities. In the eyes of local citizens, the susceptibility of the KHNP's internal server to cyber-attacks constituted yet another danger associated with nuclear energy production. These apprehensions were buttressed by the hacker's pronouncement that anyone living in proximity to the plants should vacate their homes immediately (McCurry 2014).

What was the combined impact of these challenges on South Korea's nuclear energy program? In short, the rise in anti-nuclear sentiment in relation to the scandals essentially reined in the government's nuclear power aspirations. Faced with unprecedented criticism over the safety standards and regulatory practices at domestic nuclear power plants, 
South Korea's Ministry of Trade, Industry, and Energy was compelled to drastically lower the national nuclear energy capacity target. Whereas the initial goal was to attain 59 per cent capacity by 2030 , in the aftermath of the scandals, this was reduced to a more modest 22-29 per cent (by 2035) (Ministry of Trade, Industry, and Energy 2014: 40). The justification provided for this revision was the need to avoid 'excessive expansion' of nuclear energy and, doubtlessly, was premised on the increasing concerns of citizens. As a further ramification, the KHNP agreed to permanently shut down the Kori-1 reactor in June 2017 on the advice of the central government, rendering it the first of South Korea's nuclear power units to enter the decommissioning phase. The controversies moreover necessarily imposed a significant financial burden on the KHNP: a congressional hearing in October 2013 estimated this cost to be as high as US\$2.8 billion (Cho 2013).

The overarching effect of the scandals is that South Korea's nuclear energy industry has been rendered more accountable to the public. This status quo is being reinforced by the recent corruption charges levelled against the Park Geun-hye administration, and the consequent presidential impeachment proceedings. As allegations emerged that President Park-daughter of Park Chung-hee-had colluded with a confidante in the embezzlement of large sums of public funds, over a million South Korean citizens took to the streets in protest. Their refusal to accept their president's apology and to continue to call for her resignation is stark evidence of society's diminished tolerance for government malfeasance.

\section{Conclusion: The post-Fukushima legacy of the South Korean anti-nuclear movement}

The Fukushima disaster of March 2011 was a vivid reminder for the world that nuclear power plants can cause catastrophic damage. A number of governments accordingly aborted or considerably slowed the pace of their nuclear energy programs, taking heed of rising concerns about the safety of nuclear reactors among their populaces. Yet, as we have seen, South Korea conversely pushed ahead with its ambition to become a foremost nuclear powerhouse after 3/11. This was in spite of the anti-nuclear movement gaining significant traction and mounting a concerted effort to alter policy and practice in the industry. The aim of this chapter has been to explain the limited effect of the movement through an examination of its anti-nuclear campaigns in pre- and post-Fukushima contexts. 
It found that, owing to the fact that nuclear power became firmly ensconced in Seoul's energy policy long before the advent of anti-nuclear activism, the movement faced formidable structural obstacles from its incipient stages. This entrenchment of nuclear energy occurred as a consequence of decades-long dictatorial rule, the US-South Korea alliance, and the export-oriented development model installed by former President Park Chung-hee. Early collaboration among activists on opposing nuclear energy was hampered primarily by two factors: the dictates of authoritarian leadership and the preoccupation of the South Korean citizenry with achieving democratisation.

Once the anti-nuclear movement eventually materialised in the late 1980 s, it proceeded to challenge various facets of nuclear energy policy with mixed results. In the earlier stages of its campaign, activists attained a degree of success in thwarting the construction of new nuclear power plants and radioactive waste disposals. They largely failed, though, in their post-Fukushima objectives of countering the lifespan extension of reactors due for decommissioning, and overturning county-level agreements (enacted pre-3/11) to host new nuclear power plants.

This limited policy change, it was argued, cannot solely be understood in terms of deficiencies within the movement. Rather, a combination of factors have served to constrain the opportunity structure for activists, including the insulated and top-down nature of nuclear energy policymaking in South Korea, and the integrality of nuclear power to the government's Green Growth Strategy. For its part, the movement has neglected to formulate a viable alternative to nuclear energy, which has long constituted a driving force of economic growth for the nation.

While the anti-nuclear movement failed to achieve a phase-out of nuclear power in South Korea, it would be imprecise to conclude that its efforts have been ineffectual. In fact, activists have succeeded in politicising nuclear energy and weakening its public support base. This process was facilitated by the recent revelations of endemic corruption within the industry (and government writ large), as well as the cyber-attacks targeting the more notorious nuclear reactors in the country. The movement capitalised upon these scandals to mobilise further anti-nuclear sentiment, and to fuel public mistrust in the regulation of nuclear energy. As a result, the South Korean government's policy of expanding nuclear energy is now subject to an increasingly hostile domestic atmosphere, which stands in sharp contrast to the earlier authoritarian era. Furthermore, 
the movement partially eroded the government's monopoly over nuclear energy, by compelling the industry to enhance its transparency, improve the safety of existing reactors, and to conform to greater public scrutiny. But perhaps the most significant legacy of the movement thus far is that it helped to persuade the government to scale back its target for nuclear power generation by as much as 30 per cent.

Nevertheless, South Korea remains on track to cement its status as a nuclear power stronghold. In order to change this status quo, the antinuclear movement will need to exert constant pressure, citing the lessons of Fukushima, and to formulate a feasible alternative to nuclear energy. This, in turn, will help the South Korean government to resolve its dilemma of being reliant on nuclear reactors to sustain economic growth and reduce $\mathrm{CO}_{2}$ emissions, on the one hand, and subject to rising antinuclear views from its electorate, on the other.

If Seoul continues to pursue the further development of nuclear power without establishing a consultative mechanism that adequately incorporates the views of South Korean citizens, effectively it will only add greater fuel to the anti-nuclear movement. As surmised by Yeon Hyeong-cheol of the KFEM:

Nuclear power plants are directly connected to the lives of the residents, yet the government has ignored citizens' opinions and insisted on a policy in favour of expanding nuclear power plants. Now that we have confirmed the [anti-nuclear] thoughts of the citizens, we will actively engage in movements to close down old nuclear power plants and to oppose the construction of new nuclear power plants nationwide (Choi 2014).

\section{References}

Baylon, Caroline, David Livingstone, and Roger Brunt, 2015. Cyber security at civil nuclear facilities: Understanding the risks. Chatham House Report. London: Royal Institute of International Affairs.

Cho, Mee-young, 2013. Stung by scandal, South Korea weighs up cost of nuclear energy. Reuters, 28 October.

Choi, Seung-hyeon, 2014. Referendum on Samcheok nuclear power plant ends in overwhelming opposition, a true victory for citizen autonomy: Expected to accelerate anti-nuclear movements in other regions. Kyunghyang Shinmun, 10 October. 
Dalton, Toby, and Minkyeong Cha, 2016. South Korea's nuclear energy future. The Diplomat, 23 February.

East Coast Solidarity for Anti-Nuke Group, 2012. Pamphlet. Seoul.

Hayes, Peter, and Chung-in Moon, 2011. Park Chung Hee, the CIA, and the bomb. Global Asia 6(3): 46-58.

Hermanns, Heike, 2015. South Korean nuclear energy policies and the public agenda in the 21st century. Asian Politics \& Policy 7(2): 265-82. doi.org/10.1111/aspp.12179

Hong, G. H., M. A. Hernández-Ceballos, R. L. Lozano, Y. I. Kim, H. M. Lee, S. H. Kim, S.-W. Yeh, J. P. Bolivar, and M. Baskaran, 2012. Radioactive impact in South Korea from the damaged nuclear reactors in Fukushima: Evidence of long and short range transport. Journal of Radiological Protection 32(4): 397-411. doi.org/10.1088/09524746/32/4/397

Hwang, Hae Ryong, and Shin Whan Kim, 2013. Korean nuclear power technology. In Asia's Energy Trends and Developments, vol. 2, edited by Mark Hong and Amy Lugg, 193-204. Singapore: World Scientific. doi.org/10.1142/9789814425582_0010

IAEA (International Atomic Energy Agency), 2012. IAEA completes expert mission to Kori 1 nuclear power plant in Republic of Korea. Press release, 11 June.

IAEA (International Atomic Energy Agency)-NSNI (Division of Nuclear Installation Safety), 2012. Report of the expert mission to review the station blackout event that happened at Kori 1 NPP on 9 February 2012, Republic of Korea. 4-11 June. kfem.or.kr/wp-content/uploads/ 2012/07/1419321177_zkGfGz.pdf (accessed 6 February 2017).

KHNP (Korea Hydro \& Nuclear Power), 2012. IAEA completes expert mission to Kori 1 nuclear power plant in Republic of Korea. Press release, 13 June. www.khnp.co.kr/eng/board/BRD_000201/boardView. do? pageIndex $=6 \&$ boardSeq $=1604 \& \mathrm{mnCd}=\mathrm{EN} 0501 \&$ schPageUnit $=$ 10\&searchCondition=0\&searchKeyword $=($ accessed 6 February 2017).

Kim, Se-jeong, 2015. Referendum on nuke plant turns invalid. Korea Times, 13 November. 
Korean Government, 2011. Policy Issue 0: Report of the Korean government response to the Fukushima Daiichi nuclear accident. www.oecd-nea.org/nsd/fukushima/documents/Korea_2011_ 08Policy00GovernmentResponsetoFukushimaAccident.pdf (accessed 25 January 2017).

LaForge, John, 2013-14. Defective reactor parts scandal in South Korea sees 100 indicted. Nukewatch Quarterly Winter: 7.

Lee, Myung-bak, 2010. Shifting paradigms: The road to global green growth. Global Asia 4(4): 8-12.

Leem, Sung-Jin, 2006. Unchanging vision of nuclear energy: Nuclear power policy of the South Korean government and citizens' challenge. Energy \& Environment 17(3): 439-56. doi.org/10.1260/ 095830506778119425

McCurry, Justin, 2014. South Korean nuclear operator hacked amid cyber-attack fears. Guardian, 23 December.

Ministry of Science and Technology, 2006. Je 3-cha wonjaryeok jinheung jonghap gyehoek [Third comprehensive plan for nuclear energy development]. Seoul: Ministry of Science and Technology.

Ministry of Trade, Industry, and Energy, 2014. Je 2-cha eneoji gibbon gyehoek [The second national energy plan]. Seoul: Ministry of Trade, Industry, and Energy.

Nagata, Kazuaki, 2012. Fukushima puts East Asia nuclear policies on notice. Japan Times, 1 February.

Norman, Andrew, and Gerry Nagtzaam, 2016. Decision-Making and Radioactive Waste Disposal. Abingdon: Routledge.

Sayvetz, Leah Grady, 2012. South Koreans stop plan for nuclear waste dump on Gulup Island, 1994-95. Global Nonviolent Action Database. nvdatabase.swarthmore.edu/content/south-koreans-stop-plan-nuclearwaste-dump-gulup-island-1994-95 (accessed 25 January 2017).

von Hippel, David, Sun-Jin Yun, and Myung-Rae Cho, 2011. The current status of green growth in Korea: Energy and urban security. Asia-Pacific Journal 9(44)4: 1-15.

Yi, Whan-woo, 2012. Potential nuclear risk. Korea Times, 21 May. 
This text is taken from Learning from Fukushima: Nuclear power in East Asia, edited by Peter Van Ness and Mel Gurtov, published 2017 by ANU Press, The Australian National University, Canberra, Australia.

dx.doi.org/10.22459/LF.09.2017.05 